BULLETIN Bulletin hispanique

HISPANIQUE Université Michel de Montaigne Bordeaux

$111-2 \mid 2009$

Varia

\title{
La novela europea en la Barcelona de entreguerras
} autores, críticos y traductores

\section{Diana Sanz Roig}

\section{(2) OpenEdition \\ Journals}

Edición electrónica

URL: http://journals.openedition.org/bulletinhispanique/1009

DOI: 10.4000/bulletinhispanique.1009

ISSN: 1775-3821

Editor

Presses universitaires de Bordeaux

\section{Edición impresa}

Fecha de publicación: 1 diciembre 2009

Paginación: 449-472

ISBN: 978-2-86781-617-8

ISSN: 0007-4640

Referencia electrónica

Diana Sanz Roig, "La novela europea en la Barcelona de entreguerras », Bulletin hispanique [En línea],

111-2 | 2009, Publicado el 01 diciembre 2012, consultado el 01 mayo 2019. URL : http://

journals.openedition.org/bulletinhispanique/1009; DOI : 10.4000/bulletinhispanique.1009 


\title{
La novela europea en la Barcelona de entreguerras: autores, críticos y traductores
}

\author{
Diana SANZ RoIG \\ Universitat de Barcelona
}

S'appuyant sur la comparaison entre quatre revues culturelles - La Revista (15 mai 1915-5 juin 1936), la Revista de Catalunya (1924-1938), Mirador (14 janvier 1929-10 juin1937) et Meridià (1938-1938) - et d'une publication périodique La Vanguardia (1881 à aujourd'hui), le présent travail situe le lecteur dans l'esprit pleinement européen et cosmopolite qui caractérise la presse culturelle barcelonaise de l'entre deux guerres. Prise dans l'enclave du catalanisme, la critique de l'époque joue un rôle décisif dans la diffusion du roman catalan tout en prêtant l'attention la plus fervente à la littérature universelle et, tout particulièrement, à la littérature européenne. Avec la ferme intention de redécouvrir les frémissements des littératures française, allemande ou anglo-saxonne et les foyers de renouvellement auxquels avait accès le public des lecteurs dans la Barcelone de l'entre deux guerres, nous essaierons de voir quels ont été les auteurs, les lectures, les critiques et les traducteurs qui ont éveillé le plus d'intérêt dans les pages de critique littéraire.

A partir del cotejo de cuatro revistas culturales -La Revista (15 de mayo de 1915-5 de junio de 1936), la Revista de Catalunya (1924-1938), Mirador (14 de enero de 1929-10 de junio de 1937) y Meridià (1938-1938)-, y una publicación periódica -La Vanguardia (1881-fecha actual) el siguiente trabajo se propone introducir al lector en el espiritu plenamente europeo y cosmopolita que caracterizó la prensa cultural barcelonesa de entreguerras. Engastada en el enclave del catalanismo, la crítica de la época asumió el papel decisivo de propagar la novela catalana, a la vez que demostraba su más férvida atención hacia la literatura universal y, particularmente, hacia la literatura europea. Con el firme propósito de redescubrir los pálpitos de la literatura francesa, alemana o anglosajona, y los focos de renovación que adquiría el público lector

$B H i$, Tome 111, n² 2 - décembre 2009 - p. 449 à 472. 
de la Barcelona de entreguerras, intentaremos dilucidar cuáles fueran las lecturas, los autores, los críticos y los traductores que mayor interés suscitaron en las páginas de crítica literaria.

From the comparison of four cultural and literary magazines - 'La Revista' (1915 May 15th - 1936 June5th), Revista de Catalunya' (1924-1938), Mirador (1929 January 14th - 1937 June 10th) and 'Meridià' (1938-1938), and one daily paper-'La Vanguardia' (1881-up to now), the following essay will range across the fully European and cosmopolitan mind which defined the cultural press in Barcelona between the First World War and the beginning of the Second World War. Set in the context of the Catalan political movement, the literary criticism played the decisive role of spreading the Catalan novel abroad. At the same time, we will show how this cultural criticism is interested not only in the worldwide literature but specially in the European one. With the aim of enlightening the best of French, German and English literature, and taking into account the renewal centres that Barcelona readers had access to between the two World Wars, we will try to point out the books, the authors, the reviews and the translators who ranked the highest in the pages of these literary journals.

Mots-clés: Roman européen - Critique littéraire - Traduction - Littérature catalane - Presse - Barcelone - 1914-1939 - Études de littérature comparée.

$\mathrm{E}$ N SinTONía con los cauces de la modernidad, cierto sector de la prensa cultural barcelonesa del primer tercio del siglo XX, ávida conocedora de los movimientos estéticos y las escuelas literarias, tomó en consideración la obra de André Malraux, Marcel Proust, André Maurois, Joseph Conrad, William Faulkner, Katherine Mansfield o D.H. Lawrence, defendiendo la novela detectivesca, los viajes literarios y algunas obras de pensamiento como las de Ortega, Chesterton o Berdaiev. Paralelamente, trazó las directrices de la novela, la poesía, el ensayo, la crítica y el teatro desde la producción autóctona y desde los modelos estéticos europeos a los que atendía, manifestando un meritorio esfuerzo de objetividad, de estudio de las fuentes y de interrelación cultural. Su amplitud de miras se sustentó en modelos indiscutibles como la Europe Nouvelle, la Revue de Paris, la Nouvelle Revue Française, Les Nouvelles littéraires, Candide, Marianne o Gringoire en Francia; The Atheneum, The Criterion, The Times Literary Suplement o The Manchester en Inglaterra; la Europäische Revue en Alemania; la Nuova Antologia, La Fiera Letteraria o La Critica de Nápoles, en Italia; la Revue de Genève en Suiza, o la Little Review y el Chicago Tribune, en los Estados Unidos. A las lecturas extranjeras capaces de sugerir un comentario dedicaron artículos, ensayos y trabajos monográficos con el firme propósito de redescubrir los pálpitos de 
la literatura francesa, alemana o anglosajona, y los focos de renovación que adquiría el público lector de la Barcelona de entreguerras.

En el rastreo de este amplio horizonte, resultaba obligado limitar el cotejo de nuestro estudio a un número reducido de publicaciones: cuatro revistas culturales -La Revista (15 de mayo de 1915-5 de junio de 1936), la Revista de Catalunya (1924-1938), Mirador (14 de enero de 1929- 10 de junio de 1937) y Meridià (1938-1938), y una publicación periódica - La Vanguardia (1881-2009) - nos han servido a este propósito. La primera, heredera de los propósitos del Noucentisme, privilegió la literatura europea como foco de renovación indiscutible. En sus páginas se tradujeron un nutrido número de textos extranjeros y se dieron a conocer extensos poemas, prosas y obras teatrales que en el circuito comercial parecían no tener cabida. La Revista de Catalunya, dirigida por Rovira i Virgili, primero, y Ferran Soldevila después, y otras publicaciones como la Revista de Poesia de Marià Manent (1925), o La Nova Revista (1927-1929), fundada por Josep Maria Junoy, aglutinaron un número creciente de lectores, que menos interesados por los aires orsianos de La Revista presumían de ser jóvenes burgueses, intelectuales, cosmopolitas y modernos, y hábiles conocedores de los referentes y modelos estéticos del extranjero.

Ya en los años treinta, Mirador se adelantó a la prensa de su época trazando un modelo de revista cultural que no tenía parangón en el dominio catalán y que se convertía en uno de los ejemplos periodísticos más logrados del ámbito español. Meridià, revista publicada durante la guerra, quiso tomar el relevo de su antecesor, Mirador, apostando, en un contexto de violencia, por un tipo de crítica cultural que estuviera al servicio del pueblo y de las circunstancias sin detrimento de la calidad y modernidad de sus propuestas.

Distinto es el caso de La Vanguardia, cuya prolongación en el tiempo y otros pormenores ligados al funcionamiento interno del periódico impidieron un tratamiento homogéneo de las letras europeas. A este respecto, al margen de la transformación que el diario había experimentado bajo la dirección de Modesto Sánchez Ortiz, periodista andaluz que tuvo el acierto de incorporar los nuevos bríos de Europa a través de las plumas excelentes de Santiago Rusiñol, Josep Yxart, Narcís Oller, Joan Sardà, José Soler i Miquel, Ramón Domingo Perés, o Miquel Utrillo, el espacio dedicado a las artes y las letras mantuvo en los años venideros una leve apertura pese a la incorporación de otras voces como Azorín, Wenceslao Fernández Flórez, Benjamín Jarnés, Mario Verdaguer, o el propio Gaziel. En este contexto, bajo la dirección de Miquel dels Sants Oliver, primero, y Agustí Calvet, Gaziel, después, se intenta fraguar cierta equidistancia entre los mandatos de la familia Godó 
-Ramón Godó en primer lugar-, y el carácter que anhelaban imprimir los directores de la publicación.

Sobre este telón de fondo, el siguiente trabajo se propone introducir al lector en el espíritu plenamente europeo y cosmopolita que caracterizó la prensa cultural barcelonesa de entreguerras. Influida por la fuerza moral que ejercía el catalanismo, la crítica de la época asumió el papel decisivo de difundir la novela catalana, a la vez que demostraba su más férvida atención hacia la literatura universal y, particularmente, hacia la literatura europea. En esta pugna por divulgar las tardías ensońaciones modernistas, el clasicismo del Noucentisme, o los vientos huracanados de la iconoclastia, parecía claro el empeño de favorecer todo lo que sirviera de estímulo a la normalización de la cultura catalana.

Con ocasión de la conocida polémica entre Josep Carner y Josep Maria de Sagarra ${ }^{1}$ el género narrativo tomaba el relevo en 1925 y postergaba la poesía, que hasta entonces había sido el género más ensalzado, a un segundo término. En aquel mismo año, y desde la tribuna de La Vanguardia, Gaziel pedía la creación de un premio literario, semejante al Goncourt, que se encaminara a estimular el cultivo del género en aquellos autores que ya eran novelistas o que en su defecto tenían condiciones para serlo. Convencido de la fuerza y el valor cultural de la novela, expone el autor:

He aquí mi proyecto: un premio anual de quince mil pesetas -que yo llamaría Premio Narciso Oller, en homenaje al venerable escritor que es el más genuino temperamento novelístico que ha producido la Cataluña moderna, y el implantador decisivo de un género en nuestro renacimiento literario- para recompensar al autor de la mejor novela inédita ${ }^{2}$.

Gaziel se dirige a los directores de la Fundación Bernat Metge o la Fundación Patxot, y reitera la trascendencia del género, cuyo dinamismo, a su juicio, más que la tragedia o la poesía, puede regenerar el ambiente cultural del país.

1. Vid. Josep Carner, prólogo a L'abrandament, de Carles Soldevila, Editorial Catalana, 1918, p. 11. Destacado es también el artículo de Carles Riba (firma Jordi March), "L'abrandament, novel-la de Carles Soldevila», La Veu de Catalunya, 25-XI-1918, y sobre todo, la conferencia pronunciada en el Ateneu Barcelonés el 5 de junio de 1925 y publicada en $\mathrm{La}$ Veu de Catalunya, I (7-VI-1925), y II (12-VI-1925). En Carles Riba, Obres Completes, edición de Enric Sullà, II, Crítica, 1, Barcelona, Edicions 62, 1985, pp. 99-101; y pp. 311-319.

2. Gaziel, «Pláticas literarias. En busca de las gallinas», La Vanguardia, 22-V-1925, p. 5. 
Su propuesta, sin embargo, no se materializó hasta finales de 1927 cuando un grupo de ateneístas barceloneses de la peña del doctor Joaquim Borralleres la recogieron como propia para impulsar el Premi Crexells, creado en 1928 por iniciativa privada para recompensar el trabajo de nuevos novelistas y novelas inéditas ${ }^{3}$. Las polémicas en torno al Premi Crexells llenaron muchas páginas de los diarios de la época. Desde su columna en La Vanguardia, Gaziel mostraba su desacuerdo ante el nombre del galardón, opinión que compartía con Antoni Rovira i Virgili que manifestaba su extrañeza frente a la instauración de un premio que fomentara la novelística catalana a través de un escritor «que ni fue novelista ni es probable que, de no malograrse, lo hubiese sido nunca» ${ }^{4}$.

Entre tanto, Josep Carner prologaba l'Abrandament de Carles Soldevila, en cuya declaración de principios celebraba su estilo depurado y la modernidad de su prosa. Carner la denominaba "novela novísima», y equiparaba su carácter novelesco al de La Bruyère. Sin ceder ante los nuevos postulados, pero meridianamente consciente del alcance de la novela, el príncipe de los poetas intentó cohesionar los antiguos valores, otorgando una detenida atención a la difusión y comercialización de los productos literarios. Inexcusable es decir que el mercado necesitaba acoger a escritores profesionales que pudieran ofrecer al lector productos literariamente eficaces al margen de los avatares políticos. En este sentido, los nuevos escritores, favorables a considerar la divulgación cultural como un concepto elevado, propiciaron que el libro se tratara como un objeto de mercado. Señalada fue a este respecto la Exposición del Libro Español en Buenos Aires, muestra en la que aparte de la castellana la literatura en lengua catalana fue la única literatura ibérica representada. Desde La Vanguardia, la periodista María Luz Morales se congratulaba del lugar destacado que merecía si bien lamentaba la ausencia de las letras gallegas que a pesar de contar con la Editorial Nos y el Seminario de Estudios Gallegos no había sabido exportar los frutos más logrados de su tradición. En torno al libro catalán, Morales evocaba la inmejorable representación de las ediciones de Montserrat, de la colección Bernat Metge, de las publicaciones de la Asociación Protectora de la Enseñanza Catalana,

3. Para exposiciones más detalladas véase Isidor Cònsul, «Notes sobre la història del premi Crexells», en Centenari Joan Crexells, Ateneu Barcelonès, Barcelona, 1996, o Margarida Casacuberta, «El Premi Crexells. Notes sobre cultura i novel.la en els tombants dels anys vint als trenta», Els Marges, núm. 52 (marzo 1995), pp. 19-42.

4. Gaziel, «Vida literaria. Notas a un premio», La Vanguardia, 21-XII-1928, p. 9. Desde su columna en La Vanguardia también Mario Verdaguer le dedica un extenso artículo: «Letras catalanas. Joan Crexells», 02-II-1934, p. 5. 
de las joyas editoriales de Oliva de Vilanova, de las colecciones de Gili y Verdaguer, o de las magníficas traducciones de Catalonia y Proa ${ }^{5}$.

En esta discusión sobre la novela no cabría olvidar como precedente las reflexiones de Alexandre Plana en los artículos agrupados bajo el título genérico «La novel-la». En ellos, el perspicaz crítico catalán hacía reposar sus planteamientos sobre lo que andado el tiempo desarrollarían Riba, Sagarra y Carner ${ }^{6}$. Las palabras de Riba, pronunciadas en su conferencia del Ateneu Barcelonés el 5 de junio de 1925, se encaminaban hacia una nueva generación, grupo que recibiría con agrado la consolidación de la novela. En su reseña de La Venus de la careta de Domènec Guansé, un conjunto de tres novelas breves de corte sensual-erótico, Agustí Esclassans reconocía que ante una novela de este tipo el debate entre el arte y la moral fácilmente podía reiniciarse. Sin embargo, para Esclassans, todos los avatares de la vida eran materia novelable y el resultado, más que del contenido, dependía de la manera de decirlo ${ }^{7}$. Armand Obiols, a partir de un artículo de Henri Pourrat, analiza el camino que ha seguido el arte poético, senda que en su opinión tiende hacia la poesía pura, y concluye que la novela, contrariamente, se dirige hacia otro ideal ${ }^{8}$. Para Obiols, la novela se halla en una época de renacimiento que alcanza su gloria más alta en la obra de Dostoiewsky.

A principios de los años veinte las obras traducidas en Barcelona se corresponden con autores modernos y contemporáneos como los alemanes Bonsels, Immermann, Keller, Schnitzler o Zweig; los prosistas franceses André Gide, Paul Claudel o Anatole France; en el dominio anglosajón Thomas Hardy, Max Beerbohm, Aldous Huxley, Joseph Conrad, Katherine Mansfield, Paulina Smith, Elvira A. Lewi, y Charles Dickens, o Edgar Allan Poe, entre los norteamericanos, cuyas Historias extraordinarias serían magníficamente traducidas por Carles Riba entre 1915 y 1918. El gusto por la literatura anglosajona procedía en este sentido de las filas novecentistas, d'Ors, Carner y López Picó a la cabeza. Carner, director literario de Editorial Catalana entre 1918 y 1921, se consagró a la tarea de traductor convirtiéndose en el valor principal de su colección de literatura extranjera, la Biblioteca

5. María Luz Morales, «Información catalana. Expansión cultural. El libro español en Buenos Aires. Una iniciativa del gobierno. La cooperación de los escritores catalanes. El presente y el porvenir», La Vanguardia, 30-VII-1933, p. 4.

6. Vid. Alexandre Plana, La Revista, «La novel-la», 1917, 34, pp. 101-102; y 1917, 45, 288-289. Sobre esta cuestión, clásica resulta la consulta del libro de Alan Yates Una generació sense novel.la?, Barcelona, Edicions 62, 1981.

7. Agustí Esclassans, «La Venus de la Careta de Domènec Guansé», Revista de Catalunya, agosto de 1927, núm. 38, pp. 147-150.

8. Armand Obiols, "Nòtules. Novel.la pura», Revista de Catalunya, abril de 1928, I, núm. 46, pp. 415-420. 
Literària. En 1918 publica Tom Sawyer y El elefante blanco de Mark Twain, y Una canción de Navidad y Novela de vacaciones de Charles Dickens. Ya en el marco de Edicions Proa publicará en 1931 y 1934, respectivamente, Pickwick, reseñado por la Revista de Catalunya en junio de 1931, y Las grandes esperanzas de Pi $p^{9}$. Cèsar August Jordana, por su parte, será el encargado de traducir Mrs Dalloway, de Virginia Woolf, y el autor de varios comentarios sobre H. G. Wells. A subrayar, «La guerra a l'aire», en la Revista de Catalunya, en mayo de 1938, o, con anterioridad, el trabajo de Marià Manent «La nova utopia de Wells», en enero del mismo año. Acerca de Virginia Woolf y su novela The Years, discurrirá Manent en el mismo ejemplar.

Las conocidas Lectures europees de Ramon Esquerra siguen los postulados que Sagarra había abanderado en $1925^{10}$, y se convierten en un análisis preciso y riguroso de la novela inglesa, norteamericana y francesa, fundamentalmente. Para Ezquerra, la novela será junto al libro de viajes el más lúcido reflejo de la realidad y la sociedad contemporánea. Los artículos y traducciones de Esquerra, como los de Ricardo Baeza, traductor de Óscar Wilde al castellano, primero en España y después en Buenos Aires, serán en definitiva reveladores de su vocación, gusto y carácter. En estas latitudes se inscribe también el texto de Cèsar August Jordana «Les afeccions literàries del públic anglès i americà», publicado en noviembre de 1927 en la Revista de Catalunya. Muy interesante también resulta el exhaustivo retrato que traza Rafael Tasis i Marca en el artículo "Aldous Huxley». Con respecto a su novela Point counterpoint, Tasis no vacila en afirmar que se cuenta entre las mejores obras de la época. En el cenit de su autoridad, Huxley es examinado en su faceta de hombre, novelista, artista-creador y filósofo ${ }^{11}$. El novelista inglés será también objeto de estudio en "En el reino de la utopía», artículo de José María Salaverría que a propósito de la traducción de Un mundo feliz, de Luys Santa Marina, discurre acerca de las utopías en el momento presente $^{12}$.

9. Varios han sido los trabajos dedicados a la faceta de traductor de Josep Carner. Entre ellos, cabe destacar Carles Riba, "La Fontaine traduit per J. Carner», Obres Completes, II, Barcelona, Edicions 62, 1985, pp. 249-255; LL. Cabré-M. Ortín, «Aproximació a Josep Carner, traductor. Els anys de l'Editorial Catalana», en Els Marges, 31, 1984, pp. 114-125, o Albert Manent, Josep Carner i el Noucentisme, Barcelona, Edicions 62, 1982, pp. 347-350.

10. Vid. Josep Maria de Sagarra, «La utilitat de la novel.la», La Publicitat, 10-V-1925.

11. Rafael Tasis i Marca, Revista de Catalunya, "Aldous Huxley», 15 de febrero de 1938, I, núm. 83, pp. 181-211.

12. José María Salaverría, «Ideas y notas. En el reino de las utopías», La Vanguardia, 19-XI1935, p. 7. 
Entre los escritores anglosajones, mención aparte merece la atención dedicada a Chesterton, colaborador asiduo en La Nova Revista desde 1927 en la sección «El nostre carnet». Pronto asistiremos sin embargo a la creación de otras secciones «Els amics de Chesterton», y «Obres de G. K. Chesterton», apartados que se explican ante la creciente popularidad del autor ${ }^{13}$. En agosto de 1927 Pla publica en la Revista de Catalunya "Nota sobre Chesterton»; en 1931, se publica por entregas L'home que fou dijous. Entretanto, Josep Maria Junoy encarga a Pau Romeva la traducción de sus Obras Completas, y Manent publica L'home perdurable en la Biblioteca Horitzons ${ }^{14}$. Su difusión, no obstante, se inició gracias a la traducción española de San Francisco de Asis, realizada por el mismo Manent en 1925. Esta interpretación muestra el estrecho vínculo entre los católicos ingleses y la religiosidad catalana de la época, así como una determinante recuperación de los valores franciscanos. Chesterton, escritor inglés conservador, será paradójicamente invitado con todos los honores al círculo de l'Amic de les Arts en Sitges. De su relación epistolar con Josep Carbonell i Gener, director de la revista sitgetana, se reproducen los siguientes fragmentos:

Carta de benvinguda de L'Amic de les Arts a G.K. Chesterton: «Dear mister Chesterton: In name of Friends of Fine Arts I am giving you the most hearty welcome. Please accept your wife and you these carnations, characteristic of our village. It is highly pleasing for me to know that you are among us. You that are one of my strongest admirations and also the most formidable representative of Bristish thoughts facing a secure Future». Resposta de G.K. Chesterton: «Dear senyor Carbonell $i$ Gener: I really do not know how to thank you sufficiently for your most charming and generous gesture of welcome. You are kind enough to refer to my deplorable habit of writing $[\ldots]^{15}$ ".

En la redacción de La Vanguardia, la noticia de su muerte propiciará emocionadas evocaciones de José Escofet y Augusto Assía, en la época corresponsal en Londres ${ }^{16}$.

13. Interesante resulta a este respecto el artículo de Mireia Aragay y Jacqueline Hurtley "The Chestertonization of Catalonia: G.K. Chesterton in La Revista and La Nova Revista», Journal of Interdisciplinary Literary Studies, vol. 3, num. 1, University van Amsterdam/ University of Nebraska, 1991.

14. Sobre L'home perdurable se pronunciaba Joan Sacs en «Chesterton o la Sofísitica recreativa» (A propòsit de "L'Home perdurable»), Revista de Catalunya, diciembre de 1927, núm. 42, pp. 604-617. Para consultar la nota de Pla véase «Nota sobre Chesterton», Revista de Catalunya, 15 de agosto de 1927, II, núm. 38, pp. 122-131.

15. Vid. L'Amic de les Arts, «G.K. Chesterton a Sitges», mayo de 1926, Any I, núm. 2, p. 2. 16. José Escofet, «Espejismos. Chesterton o el apasionado vidente», La Vanguardia, 20-VI- 
La obra de James Joyce, escasamente comentada en la prensa catalana, fue sin embargo traducida parcialmente en algunas publicaciones como Hèlix o D'Ací D'allà, revista que publicó en 1926 y 1930 las narraciones «Evelina» $\mathrm{y}$ «Un nuvolet» en traducción de Millàs Raurell y Josep Pius i Lluís ${ }^{17}$. No obstante, era la redacción de La Revista la primera que celebraba su fantasía moral en marzo de 1921 y traducía algunos poemas en enero de 1924 a cargo del mismo Raurell. Al escritor irlandés se refería de nuevo López Picó en su sección «Moralitats i Pretextos» en diciembre de 1924. Probablemente, y como insinúa Domingo Ródenas, su figura fue introducida en España por Antonio Marichalar quien desde su colaboración en The Criterion, la revista de Eliot, se familiarizó con los escritores anglosajones y publicaría, con respecto a Joyce, el artículo "James Joyce en su laberinto» en noviembre de $1924^{18}$. Pese a este texto y al empeño de Marichalar por difundir la obra joyceana cabe señalar el precedente de 1921 en la revista catalana.

La muerte del novelista y dramaturgo John Galsworthy, galardonado con el Premio Nobel en 1932 -Rudyard Kipling lo había sido en 1927-, propicia el recuerdo emotivo de María Luz Morales que en el artículo «Galsworthy y las mujeres» lamenta que sólo el espaldarazo del galardón haya alentado a traductores y editores a reforzar su nombre en el mercado del libro español ${ }^{19}$. En el caso de Hardy, la Revista de Catalunya publicará en enero de 1928 una nota necrológica en la que lo califica como el mejor escritor de la edad contemporánea. En otro lugar la redacción se referirá a un artículo publicado sobre el autor en el Manchester Guardian. En la revista Meridià, Lluís Montanyà, autor del artículo «L'esfinx i la quimera (A propòsit d'alguns joves poetes anglesos)", que se ocupaba de la posición de los poetas ingleses ante la urgencia de la guerra, examina también la actitud de otros escritores anglófonos como el novelista Theodore Dreiser que, invitado por la Asociación Internacional de Escritores, se aloja en Barcelona como primera etapa de su viaje por la España Republicana ${ }^{20}$.

1936, p. 5, y Augusto Assía, "Crónicas de Inglaterra. Chesterton, cruzado de la fe. Poeta, controversista, filósofo y utopista», 21-VI-1936, p. 5.

17. James Joyce, «Evelina», traducción de Millàs Raurell, en D'Ací i d'Allà, febrero de 1926, núm. 98, pp. 432-433, y «Un nuvolet», traducción de Josep Pius i Lluís, septiembre de 1930, núm. 153, pp. 305-306, 308-309, y 322.

18. Vid. Domingo Ródenas, Antonio Marichalar, el embajador europeo de la Generación del 27, Madrid, Fundación Santander Central Hispano, 2002, p. XXX.

19. María Luz Morales, "Temas femeninos. Galsworthy y las mujeres», La Vanguardia, 10-II-1933, p. 5. Véase también José Betancourt, «Nuestro tiempo. John Galsworthy», La Vanguardia, 16-XI-1932, p. 5.

20. Vid. Lluís Montanyà, «Registre d'entrada. Theodor Dreiser», Meridià, núm. 31, 12VIII-1938, p. 6. 
Entre los prosistas franceses, en La Revista cabe destacar al autor romántico Prosper Mérimée, a Paul Claudel, Anatole France, Charles Louis Philippe o Pierre Mac Orlan, pseudónimo de Pierre Dumarchey. Sobre su labor como novelista reflexionaba Lluís Montanyà en "Pierre Mac Orlan, la novel.la d'aventures i el fantàstic social», trabajo que junto a una completa reseńa biográfica se publicaba en la Revista de Catalunya en febrero de 1938. Jaume Bofill i Ferro será, por su parte, el encargado de traducir el genio proustiano si bien Gaziel, el ilustre director de La Vanguardia, se definía en este sentido como su más entusiasta defensor. Sin embargo, a tenor de las declaraciones de Josep Pla en El quadern gris, todo parece apuntar a la figura del doctor Quim Borralleres como el apasionado lector y comentarista de las novelas del escritor francés en la tertulia del Ateneu ${ }^{21}$. A este respecto, Gaziel reconocía el influjo de la cultura francesa y cómo su tradición había condicionado significativamente su trayectoria intelectual y profesional. A ella se dedicó especialmente no sólo como lector sino como corresponsal y crítico de Voltaire, Montaigne, Flaubert, Molière, Renan, Stendhal, Chateaubriand, Anatole France, Proust o el propio Valéry, de quien tradujo al catalán junto a Miquel Forteza Le cimetière marin, o L'Ébauche d'un serpent. Este interés también queda bien representado en sus conocidas crónicas parisinas publicadas en La Veu de Catalunya, sus colaboraciones periodísticas, u otros trabajos como Meditacions en el desert.

En Miradory La Vanguardia André Gide será referido con frecuencia. Sobre Gide y el autor de En busca del tiempo perdido interesante resulta el artículo "L'esperit de la literatura moderna», texto de la Revista de Catalunya (octubre de 1929) en el que se menciona también a Duhamel y Jean Giraudoux. A propósito de la traducción de Vuelo nocturno de Antoine de Saint-Exupéry, Benjamín Jarnés comenta su admirable preludio, escrito por Gide, y elogia el acierto de sus reflexiones ${ }^{22}$. Avanzada la década de los años treinta, muy importante será la recepción de André Malraux. Particularmente destacada

21. Este dato ha sido también confirmado por Joaquim Molas en "Proust a Catalunya», en Serra d'Or, XIII, 1971, pp. 27-278. Vid. Joaquim Molas, Lectures crítiques, Edicions 62, Barcelona, pp. 11-16. Sobre las opiniones de Gaziel en torno a Proust pueden consultarse los artículos publicados en la sección «Pláticas literarias» de La Vanguardia. Vid. «Estructura y acción en la obra de Marcel Proust», 16 de enero de 1925, p. 5; y 23 de enero de 1925, p. 5. El periodista catalán disiente de los juicios de Benjamin Crémieux y Ortega y Gasset, y retoma el debate que Eugenio d'Ors había inaugurado en El Día Gráfico. Vid. «Proust», 17-IV-1921. Cito por Eugenio d'Ors, Glosari, selección de Josep Murgades, Barcelona, Edicions 62, 1990, p. 330. D'Ors definía entonces $A$ la recherche du temps perdu como una obra invertebrada. En 1925 desmentirá sus opiniones.

22. Vid. Benjamín Jarnés, «Letras. Alrededor de un vuelo», La Vanguardia, 30-IX-1932, p. 5 . 
es la reseña de L'Espoir por Lluís Montanyà en la Revista de Catalunya, o los textos aparecidos en la revista Meridià ${ }^{23}$.

De Italia provienen las narraciones de Pestalozzi, Giovanni Papini, Massimo Bontempelli, Italo Svevo, o Alberto Moravia, en traducción de Miquel Llor. El Gog de Papini será traducido por Mario Verdaguer. El propio escritor reseña la obra en su columna de La Vanguardia el 3 de mayo de 1931. Lo harán también Benjamín Jarnés y Juan Ramón Masoliver en los artículos «Otro diablo cojuelo» (20-V-1931) y «Un nuevo libro polémico de Papini» (11-I-1935), respectivamente.

Andreu Nin, finalmente, será el gran traductor de la literatura rusa. Pilniak, Tolstoy y Dostoiewsky serán magistralmente versionados. En La Revista documentamos dos cuentos de Tolstoy y André Sobol, El prec d'una mare y Princesa, respectivamente. Sin duda, los cambios históricos y sociales que experimentará Rusia en los años de entreguerras provocarán la atención de todo el continente europeo. En este sentido, varios serán los artículos y libros publicados sobre las transformaciones que se estaban desarrollando. José Escofet, colaborador frecuente de La Vanguardia, escribe con respecto a la publicación en castellano del último libro de Liam O’Flaherty sobre la Rusia soviética: «No es una gota de agua en el mar ni un grano de trigo en el granero. Pronto se podrá formar un Himalaya con los libros sobre Rusia que aparecen todos los días» ${ }^{24}$. La difusión extraordinaria de Dostoiewsky, cuyo centenario se había celebrado en 1921, alienta varios artículos en la Revista de Catalunya. Rovira i Virgili seńala los paralelismos existentes entre el pueblo ruso y el catalán, ambos estigmatizados por «el neguit moral, la instrospecció insistent, la confessió de les pròpies defallences i caigudes [...]» ${ }^{25}$. En esta publicación se reproducen también un artículo del escritor ruso publicado en la Revue Européenne, dos cartas publicadas en la Revue des Vivants, y una reproducción del artículo "La novel.la soviètica (1921-1926)» de Nina Troll publicado en la revista parisina Le Monde Slave ${ }^{26}$. Similar acogida denotará su figura en las páginas de La Vanguardia, publicación que dará cuenta y razón

23. Vid. Lluís Montanyà, Revista de Catalunya, "André Malraux o l'Esperança», mayo de 1938, núm. 86, pp. 133-143; y César M. Arconada, Meridià, «André Malraux i Waldo Frank. El que porten els uns i el que s'enduen els altres», 17-VI-1938, núm. 23, p. 3.

24. José Escofet, La Vanguardia, Actualidades, "Un escritor independiente en Rusia», 12III-1932, p. 5.

25. Antoni Rovira i Virgili, «Literats i literaturas», Revista de Catalunya, gener-febrer, 1929, pp. 1-22.

26. Vid. "Dues cartes de Dostoievski», Revista de Catalunya, noviembre-diciembre de 1929, II, núm. 60, pp. 401-411; Nina Troll [A.R.V. traductor], «La novel-la soviètica (19211926)», Revista de Catalunya, septiembre de 1927, II, núm. 39, pp. 279-293. 
del legado de «uno de los primeros maestros de la novela contemporánea» ${ }^{27}$. Desde su columna en el rotativo barcelonés, Benjamín Jarnés retrata y revisa la figura de Tolstoy a partir de la publicación de La tragedia sexual de Léon Tolstoy, de José Kallinikov. Al parecer del crítico, Tolstoy vivió sumido en el dolor, y fue precisamente este sentimiento el que le estimuló la búsqueda de mayores hallazgos. Entre sus novelas más logradas, destaca la escritura de Resurrección ${ }^{28}$. La pluma de Nin se sumará a esta afluencia de noticias sobre la literatura rusa con el texto "Grandesa i decadència de la novel.la soviètica», publicado en la Revista de Catalunya en mayo de 1934. En esta publicación aparecerán también una reseńa sobre la traducción en Proa de La mort d'Ivan Ílitx, a cargo de F. Payarols; la reproducción del artículo «Tolstoi» de Alfred Gallard publicado en La Revista, y un texto de Ambrosi Carrión intitulado "Lescriptor i el poble» ${ }^{29}$. Por otro lado, una selección de narraciones de Chéjov serán publicadas por la colección $A$ tot vent, mientras las Edicions de l'Arc de Barà publican en un volumen dos ensayos "Lenin» $\mathrm{y}$ "El pagès rus», de Màxim Gorki traducidos por Ventura Gassol y Josep Carner.

En los albores de los ańos treinta, y muy especialmente durante la guerra civil, el arte y la literatura rusa cobrarán un renovado sentido. La segunda época de Mirador, amparada bajo la sombra del PSUC (Partit Socialista Unificat de Catalunya), y la línea editorial de Meridià manifestarán evidentes filias al nuevo pensamiento de la URSS. No obstante, muchos de sus artículos ratificarán también la estimación por los escritores del pasado: la obra de Pushkin o Maxim Gorki, o la dramática de Ostrovski serán debidamente examinadas ${ }^{30}$. Rafael Moragas relata cómo a través del periodista valenciano Luis Morote conocemos una carta de Gorki en la que el escritor ruso agradece muy sinceramente la ayuda que le prestaron los intelectuales catalanes y castellanos después de su encarcelamiento, en 1905, en la ciudadela del San

27. Vid. José Betancort, «Nuestro tiempo. Los augurios de Dostoyewski», La Vanguardia, 23-I-1925, pp. 5 y 6; o Benjamín Jarnés, «Paisajes. Consideración de Dostoievski», La Vanguardia, 01-11-1931, p. 7.

28. Benjamín Jarnés, «Letras. Tolstoy, sombrío y voluptuoso», La Vanguardia, 05-II-1932, p. 7.

29. Vid. Revista de Catalunya, noviembre de 1930, "Tolstoi», La mort d'Ivan Ílitx», traducción de F. Payarols, Edicions Proa, 1930; Revista de Catalunya, «Tolstoi», agosto de 1929, pp. 178-181. Reproducción del artículo de Alfred Gallard publicado en La Revista, junio-diciembre de 1928; y, Ambrosi Carrión, Revista de Catalunya, "L'escriptor i el poble», septiembre de 1929, pp. 216-229.

30. Vid. Rafael Moragas, Meridià, "Un record periodístic emocionant. Una abraçada de Gorki per a tots els escriptors catalans», 05-VIII-1938, núm. 30, p. 3; D.G. [Doménec Guansé, probablemente], Meridià, "Actualitat d'A.N. Ostrovski», 17-VI-1938, núm. 23, p. 7; o Anónimo, Meridià, «Maxim Gorki», 24-VI-1938, núm. 24, p. 6. 
Petersburgo zarista. Como explica Moragas, el escritor valenciano visitó a Gorki en marzo de 1905, en una pensión de familia de un pueblo del Báltico, cercano a Bilderlinbshoff, que los rusos denominaron "pequeño Edimburgo». Entre los escritores catalanes y castellanos que menciona Gorki figuran Miquel Utrillo, Pérez Galdós, Rusińol, Felip Cortiella, Unamuno, Salvador Vilaregut, Guimerà, Ramón Casas, Navarro Ledesma, Enric Borràs, Enric Granados, Puig i Ferrater, Azorín, Rubén Darío, Gutiérrez Solana, Pere Corominas, Valle Inclán, Rovira i Virgili, Ricardo Baroja, Lluís Companys, Jacinto Benavente, Lluís Bagaria, Josep Clarà, Federico Urales, Darío de Regoyos, Silverio Lanza, Joaquín Pena, o Víctor Català, entre otros. A su muerte, su personalidad será recordada por el periodista Pedro Gual Villalba en «Gorki y los bolcheviques», y por José María Salaverría en el artículo obituario "Otra imagen de Máximo Gorki» ${ }^{31}$. También en La Vanguardia, José Betancourt se refiere a Liam O’Flaherty como el "Gorki irlandés». En Mirador, Joan Ramón Masoliver, en su crónica del Festival de Venecia de 1934, destacará elogiosamente The man of Aran, versión cinematográfica de la obra de este escritor ${ }^{32}$.

Con todo, los intereses con respecto a la novela del matutino barcelonés se deslizarán sin embargo hacia posiciones mucho más conservadoras y comerciales. Desde tales planteamientos, el espacio dedicado a las artes y a la literatura europea será en este sentido menor, disperso y fragmentario. Así, frente a tentativas más originales y arriesgadas, los críticos de la publicación, atrapados en este sentido por las directrices de Ramón Godó, dirigirán su atención hacia las novelas de aventuras, los libros de viajes, los folletines sentimentales, o la novela detectivesca. A modo de ejemplo, en la sección titulada "Libros y Revistas», espacio que por otra parte documentamos de forma intermitente, leemos elogiosos ditirambos a novelas como Los tres hombres o El hombre de siniestro, del folletinista Edgar Wallace, publicadas por la colección Fama y Femenina, respectivamente, de la editorial Juventud; El infierno verde, de Gonzalo de Reparaz, en la colección aventura de la misma editorial; o las novelas de Peter B. Kyne, el escritor norteamericano en cuyas obras se inspiraba «El caballero del mar», pseudónimo de Julián Amich Bert.

En esta tarea de elevación cultural, al margen de las columnas de prensa que construían la opinión pública y moldeaban el gusto del lector,

31. Pedro Gual Villalba, «Literatura y política en la Unión Soviética. Gorki y los bolcheviques», La Vanguardia, 27-VI-1936, p. 5, y José María Salaverría, «Ideas y notas. Otra imagen de Máximo Gorki», 10-VII-1936, p. 5.

32. Vid. «Nuestro tiempo. El Gorky irlandés», 06-II-1932, p. 5, y Joan Ramón Masoliver, "Conclusions del cinema a Venecia», La Vanguardia, 18-X-1934, núm. 297, p. 4. 
fundamentales resultan los esfuerzos de las editoriales de la época. El escenario de entreguerras manifiesta en este sentido un notable crecimiento que se traduce en nuevas y numerosas colecciones y bibliotecas. Así, en el sector editorial irrumpen importantes logros del Noucentisme como la Fundación Bernat Metge (1922), la colección Els Nostres Clàssics (1924) o la Col-lecció popular dels coneixements indispensables MINERVA (1915-1922). Muy destacada fue también la tarea de Editorial Catalana (1917-1924) que contenía precisamente dos colecciones: Biblioteca Literària, orientada a difundir las traducciones de los clásicos de todos los tiempos, y Biblioteca Catalana, que albergaba autores locales sin distinción de grupos o movimientos.

Las «Publicacions de La Revista» (1916), prolongación de la misma; la Col-lecció de Clàssics Barcino; A tot vent, de la editorial Proa (1928), que se inauguraba con la traducción de Manon Lescaut de Prévost, y se aventuraba entre otros clásicos con El rojo y el negro de Stendhal, en traducción de Just Cabot; la colección de la Nova Revista, de tradición cristiana, que introdujo a Chesterton al catalán; las colecciones populares La Novel.la d'Ara (1923), La Novel.la Estrangera, o Les Ales Esteses, de la Llibreria Catalònia (1924); Editorial Diana o La Mirada, para los autores locales; la colección Quaderns Literaris (1934), que en 1937 se convertiría en la Biblioteca Rosa dels Vents de José Janés, o, bajo la iniciativa de Antoni López Llausàs, la Biblioteca Univers de Carles Soldevila, inaugurada con la traducción del Candide de Voltaire, fueron sin duda otras iniciativas que enriquecieron el panorama editorial de los ańos veinte y treinta. En la Biblioteca Univers, orientada sobre todo hacia los escritores del XIX, se distinguen Dickens, Dumas, Baudelaire, Daudet, Maurois, Tolstoy, Dostoiewsky o Turgueniev. En Proa sobresalen los grandes prosistas del XIX -Dickens, Scott, Balzac, Stendhal- pero también otros autores más contemporáneos como Proust, Huxley, Woolf, Moravia o Duhamel.

Al margen de la colección $A$ tot vent, que en 1939 ya había publicado 92 títulos, Proa también impulsó otras colecciones como Històries curtes o Els d'Ara, donde se publicaron escritores de narrativa breve como Maupassant o Zweig, sin duda el narrador alemán más valorado, y otros autores más controvertidos como Gide. Asimismo, tuvo la feliz intuición de traducir a Remarque, escritor que cosechaba grandes éxitos con Res de nou a l'Oest y que alcanzará notoria repercusión en las páginas de la prensa. A tot vent había sido fundada en Badalona en 1928 por Josep Queralt y Marcel.lí Antic. En 1935, dirigida por Puig i Ferrater, incorporaría la colección La Mirada, que publicaba las obras de los escritores catalanes. En la Biblioteca Rosa dels Vents asomaron finalmente las firmas más renovadoras, y a veces menos traducidas, como Gide, Hemingway, Mansfield o Jean Giraudoux. 
En torno a las relaciones entre la novela y la biografía, la prensa barcelonesa también se hizo eco de los debates que se habían generado. Sin duda, el interés que había aflorado en los años veinte por el género biográfico marcó la sensibilidad y atención de los escritores y críticos catalanes que se emparejaron con los gustos y aficiones de otros compañeros de su generación. Benjamín Jarnés, desde la tribuna de La Vanguardia, justificaba el afán de leer biografías en razón de la carencia actual de figuras de excepción: «la verdad es que para hallar hoy hombres-resúmenes, hombres índices, es preciso volverse de espaldas al presente y rebuscar en la historia» ${ }^{33}$. También Carles Soldevila, desde su sección "Acotaciones», parecía interesarse por este asunto y constataba en España la moda de las biografías noveladas, después de haberse impuesto en Francia, Inglaterra, y Alemania ${ }^{34}$. Si bien reconocía su afición, Soldevila lamentaba que este movimiento no impulsara la escritura de dignos ejemplos que pudieran equipararse a lo que modernamente se había publicado en otros países. Frente a las biografías editadas en Madrid o Barcelona, el crítico reconocía su desinterés y observaba que los autores españoles habían apartado a las figuras capitales para retratar las vidas de personajes de segunda fila. En este sentido, Soldevila remarcaba el talento de Stephan Zweig, cuyo oficio en la materia le permitía insuflar a sus criaturas vidas y avatares intensos. A su juicio, España no sólo carecía de una tradición memorialista y del gusto por escribir cartas o confesiones, sino que el orgullo, la pereza, y la escasa difusión de la cultura literaria, habían impedido recopilar una documentación semejante a aquella de que disponían los biógrafos ingleses y franceses. Tras estas observaciones, Soldevila recalaba en el obstáculo principal que dificultaba el desarrollo del género: la ausencia de plumas tan dotadas como las de Maurois, Stratchey, Ludwig, o Zweig ${ }^{35}$. A

33. Benjamín Jarnés, «Letras. Coros, masas, orfeones», La Vanguardia, 17-VI-1932, p. 5. Su interés por el género también se verá reflejado en «Paisajes. Consideración de Dostoievski», La Vanguardia, 01-XI-1931, p. 7, o «Arte. Conmemoración de Wagner», La Vanguardia, 04VIII-1933, p. 3.

34. Carles Soldevila, "Acotaciones. Biografías y novelas», La Vanguardia, 06-II-1935, p. 5.

35. Benjamín Jarnés se referirá con frecuencia al talento de Zweig como escritor de biografías. Muy ilustrativos son a este respecto los artículos «Cimas bajo el horizonte», «Almas de enlace», o "Escuela de humanidad», trabajos en los que comenta, respectivamente, la publicación de Fouché, La lucha contra el demonio, sobre Hölderlin, Kleist y Nietzsche, y Tres poetas de su vida, libro en el que retrata a Stendhal, Casanova, y Tolstoy. Vid. Benjamín Jarnés, "Paisajes. Cimas bajo el horizonte», La Vanguardia, 07-VIII-1931, p. 3; «Letras. Almas de enlace», La Vanguardia, 28-III-1934, p. 3, y "Letras. Escuela de humanidad», La Vanguardia, 28-XI-1934, p. 5. Interesante también resulta el texto de Gutiérrez Gili «Momentos estelares. Angustia del devenir», La Vanguardia, 05-VIII-1933, pp. 3 y 4. 
este respecto, el crítico mostraba su descontento ante la necesidad creciente de acudir a obras extranjeras para conocer la biografía de ilustres españoles. Por el contrario, el crítico catalán señalaba la escasa calidad de las biografías españolas que desbrozaban la vida de insignes forasteros.

Entre sus preferencias, Soldevila destaca Byron y Disraeli, de Maurois -José Betancourt se referirá a su biografía de Schelley ${ }^{36}$-; Napoleón, de Ludwig; Isabel I y el conde de Essex, de Stratchey, y Fouché y María Antonieta, de Stefan Zweig. Ahora bien, es precisamente el talento novelístico de sus autores el que en mayor medida garantizaba a su juicio el éxito de sus biografías. Tomando en consideración la ajustada frontera entre la novela y la biografía, límite que para Soldevila estaba todavía por trazar, parecía claro que la popularidad del género biográfico no procedía ni de la documentación compilada, ni de su rigurosidad histórica, sino de las capacidades novelescas que habían sazonado el conjunto "con la sal y la pimienta de la literatura». Con este procedimiento, el don imaginativo de Dumas podía equipararse a la fantasía de Zweig. Pese a tal acercamiento, Soldevila consideraba improbable que la biografía llegara a suplir por completo a las obras de ficción. La biografía -explicaba el crítico- retrata exclusivamente a personajes, hombres, y mujeres excepcionales que se distinguieron por su capacidad, o por su destino. Los protagonistas de la novela, por el contrario, se identificaban con la gente corriente; de ahí que suscitaran inusitada simpatía.

De entre los artículos dedicados a la teoría del género, destacan en Mirador los textos de Guillermo Díaz-Plaja que a tenor de las discusiones de André Maurois, en Francia, o Lytton Stratchey, en Inglaterra, reflexionaba sobre las particularidades de la biografía ${ }^{37}$.

En el contexto del Noucentisme y su recuperación cultural y lingüística -recordemos que su inicio, 1906, coincide con el Primer Congreso Internacional de la Lengua Catalana-, se inscribe la empresa de la Fundación Bernat Metge, dirigida por Joan Estelrich bajo la iniciativa de Francesc Cambó que por su parte se había inspirado en la tarea de Guillaume Budé

36. José Betancourt, «Nuestro tiempo. Familia de almas, La Vanguardia, 02-IX-1932, p. 3 .

37. A este respecto, pueden consultarse los siguientes artículos: Guillermo Díaz-Plaja, "Literatura biogràfica», Mirador, núm. 149, 10-XII-1931, p. 6; "Més sobre biografia», Mirador, núm. 151, 25-XII-1931, p. 5; «Biografies russes», Mirador, núm. 152, 31-XII1931, p. 4; "Hagiografia i humor», Mirador, núm. 152, 31-XII-1931, p. 6; y "Catàleg i finestra. Vossler i Lope de Vega», Mirador, núm. 275, 10-V-1934, p. 6. 
en Francia. Cambó, en la cena celebrada en el hotel Ritz el 9 de abril de 1923 con motivo de la aparición del primer volumen de la colección de clásicos griegos y latinos -De la natura, de Lucrecio, traducida y prologada por Joaquim Balcells, insistía en el viejo ideal de crear una cultura humanista que aparte de traducir al catalán los clásicos griegos y latinos creara una nueva generación de humanistas. Con este propósito, se dieron cita en la Fundación los profesores y conferenciantes extranjeros más prestigiosos del momento: Karl Vossler, Ernst Robert Curtius, Antoine Meillet o Tadeo Zielinski. Con la voluntad de conectar el país con los clásicos de todos los tiempos y, particularmente, con los clásicos de la Antigüedad, se consolidaba así una generación de traductores -Joan Maragall y Carles Riba, en cabezaque incorporaban tempranamente la traducción de los escritores griegos y latinos con la voluntad de reactivar el movimiento literario renaciente. Todos ellos, conscientes de la circunstancia compartida, se afanaron en acortar la distancia cultural con el resto de Europa socializando la lectura como instrumento de educación. De tal guisa se pretende introducir el common reader dirigiendo la atención hacia editoriales de la talla de The Albatross o Tauchnitz. En la Revista de Catalunya Cèsar August Jordana destacará por ejemplo la calidad y el buen acierto de las colecciones de los Penguin Books, de Penguin Shakespeare, Penguin Parade y Pelikan Books.

En el plano de las empresas o eventos que coadyuvaron al firme propósito de acortar la distancia cultural entre Cataluña y el resto de Europa mención aparte merece el esfuerzo del Conferencia Club, el ciclo de ponencias organizadas en el hotel Ritz que consiguió constituirse como una auténtica plataforma de la cultura. A sus reuniones se dieron cita los más ilustres conferenciantes, escritores y profesores europeos que lograron mantener el interés de un auditorio heterogéneo. En este mismo sentido, adquiere especial protagonismo la creación del PEN Club catalán. Siguiendo la iniciativa de Catherine Amy Dawson Scott - que el 5 de octubre de 1921 había convocado la primera reunión del PEN Club inglés para albergar a poetas, dramaturgos, ensayistas, editores y novelistas-, el 19 de abril de 1922 se celebraba en el Hotel Ritz de Barcelona el primer encuentro de su homónimo catalán. Entre los intelectuales y escritores extranjeros que acudieron a sus instalaciones, el PEN recibía el 5 de mayo del mismo año a Jules Romains, que se hallaba en Barcelona impartiendo un ciclo de conferencias en el Instituto Francés y que había publicado en la Nouvelle Revue Française un artículo sobre literatura catalana. Asimismo, la asociación establecía vínculos con otros escritores como Paul Valéry, miembro fundador del PEN Club francés que en mayo de 1924 agradecía la cálida acogida que había recibido en Barcelona. El poeta francés disertaría también en el Conferencia Club en mayo de 1933, 
fecha en la que iba a coincidir con la ponencia del biógrafo Emil Ludwig. De la crónica de su disertación se infiere la estima que suscitaba el poeta en la prensa catalana: «Paul Valéry es acaso, con André Gide, la más alta representación de las letras francesas contemporáneas» ${ }^{38}$. En conversación con Frédéric Lefèvre, el poeta recuerda su estancia barcelonesa con estas palabras:

...Je ne saurais vous dire à quel point j’ai été frappé par l'activité
intellectuelle de la capitale de la Catalogne. Il y a là d'admirables
bibliothèques comme celle de l'Ateneu, qui devraient faire envie à bien
des cités. Barcelone est sans doute actuellement le seul grand port de
l'Europe dont la vie intellectuelle soit comparable à la vie industrielle et
commerciale. Je n'insiste pas. Un détail vous donnera quelque idée de ce
qui est possible et de ce qui se fait à Barcelone. Une traduction de Platon
fort bien imprimée, sur beau papier fabriqué dans le pays, y paraît
actuellement -grec et catalan en regard- sous la direction de quelques
hellénistes distingués. Songez que la langue catalane est la langue d'un
petit pays; songez au nombre probable des lecteurs de Platon dans cette
population restreinte, songez aux conditions matérielles de l'entreprise,
vous jugerez alors de sa signification ${ }^{39}$.

Sin duda, la iniciativa del PEN, que con el tiempo se extendería a muchos países europeos, significó un punto de inflexión en el terreno político y cultural ya que no sólo atendía estructuras estatales sino una enorme diversidad de lenguas y culturas. Reunidos en fraternal encuentro, los miembros del PEN celebraron en Barcelona su XIII Congreso, presidido por Wells, Pompeu Fabra, Benjamin Crémieux y Herman Ould. Del 20 al 25 de mayo de 1935 se dan cita en la ciudad condal los escritores e intelectuales europeos más destacados del momento. Como explica Josep S. Cid, el lunes 20 los delegados fueron recibidos por el gobernador general interino de Cataluña, Pich i Pon, cuyas palabras fueron agradecidas por el delegado francés Benjamin Crémieux. Por la noche, en el Círculo Artístico, los artistas y músicos catalanes obsequiaron a los escritores extranjeros con un recital de Concepció Badia, acompañada por Pau Casals y Robert Gerhard ${ }^{40}$. Desde la

38. Anónimo, «Paul Valéry en Barcelona. La personalidad del poeta en el Conferencia Club», La Vanguardia, 09-V-1933, p. 8.

39. Vid. «En Espagne», entrevista de Frédréric Lefèvre a Paul Valéry en su sección «Une heure avec...». Cito por Michel Jarrety, Paul Valéry. Très au-dessus d'une pensée secrète. Entretiens avec Frédéric Lefevre, Editions de Fallois, Paris, 2006, pp. 92-96.

40. Josep Cid ha explicado con detalle la historia de su fundación en El centre català del PEN: 70 anys de història, Barcelona, Ayuntamiento de Barcelona, 1992. 
tribuna de La Vanguardia, José Escofet, el 31 de mayo de 1935, se hacía eco del evento y destacaba su valor de propaganda y promoción de un país y su cultura. Al margen de fomentar la industria turística y el intercambio entre los intelectuales, Escofet remarca con Wells la gran misión de las jornadas: defender la libertad del pensamiento contra la represión política. En este sentido, adquiere particular relieve la crítica y censura que los escritores del PEN realizan contra el gobierno alemán. Escofet alude al discurso del expatriado Klaus Mann, aplaudido efusivamente por los concurrentes, y señala la relevancia del acercamiento de los escritores «cuando el mundo parece haber perdido el equilibrio y los nacionalismos hiperestésicos vuelven a encresparse y a mirarse unos a otros de soslayo». En un elogiable intento de compensar los daños espirituales que había causado la Primera Guerra Mundial, el PEN intentaba aproximar la cultura y las naciones.

En relación con las estadías barcelonesas de escritores y periodistas extranjeros, e, inversamente, junto a las corresponsalías de escritores y periodistas catalanes, documentamos una destacada voluntad por resarcir el ámbito de la crítica con juicios certeros y orientaciones precisas, didácticas y eficaces. Si bien la sección sólo se prolongará durante un año, La Revista incluye, en 1925, el espacio intitulado «La crítica a l'estranger». En sus páginas se oculta el firme propósito de elevar el nivel cultural y literario del país. En este objetivo, no muy distante del que había perfilado Ortega en su teoría de la minoría selecta, la revista debe informar, mostrar las obras literarias, valorarlas y juzgarlas. La prensa barcelonesa, sin embargo, y a diferencia de los principios que defendía Ortega, no juzgará que los tiempos de crisis incapaciten a una sociedad «para alumbrar lo que lleva en su fondo». En palabras de Teresa Iribarren, prologuista a la reedición del volumen de Lectures europees, el crítico catalán Ramon Esquerra es el único que dedica un capítulo a la dimensión de maître à penser del autor, del hacedor de una nueva cultura. Esquerra transita el espinoso asunto de la crisis de Occidente y comenta algunos textos de Spengler, Ortega, o Berdaiev. Iribarren añade que el ideario y la praxis intelectual del crítico son herederas del europeísmo briandista que representaba Maurois, para quien el intelectual podía ayudar a los pueblos a su más profundo conocimiento. En este orden de cosas, $\mathrm{La}$ Revista publica en 1922 la encuesta «Entre la crítica i l'ideal».

Si en los primeros años la crítica barcelonesa es sobre todo impresionista o periodística, con el nuevo rumbo de los acontecimientos históricos se transforma en una crítica de orientación que pretende dirigir y educar el gusto del lector. Influye el modelo de d'Ors, Benedetto Croce, De Sanctis, Vossler, Thibaudet, o Gerard Bauer, crítico francés invitado al Conferencia Club el 20 de junio de 1931. Precisamente en su ciclo de conferencias 
curiosa es la participación de René Benjamin, escritor y periodista del diario L’Action française que dirigía con puño firme Charles Maurras, autor muy seguido en la Peńa del Ateneu. Benjamin disertó en el Conferencia Club el 2 de mayo de 1931 con la ponencia «De l'Art dangereux des conférences: ceux qui les commettent, ceux qui les subissent». El influjo de la crítica francesa será refrendado en numerosos artículos. De hecho, y a modo de inciso, cabe recordar que el francés fue la lengua más escuchada en los actos del Conferencia Club, institución que privilegiaba sobre los demás el grupo de escritores y críticos del país vecino. Mientras un crítico anónimo comentaba en Mirador un artículo de Jean Cassou publicado en la revista francesa Formes, Just Cabot -director de Mirador desde 1931 hasta la Guerra Civilrefería como modelo a André Levinson, crítico de libros, danza y music-hall en el Candide. Para Carles Riba, en un artículo sobre De Sanctis, la crítica tiene una función de pedagogía, de valoración de la obra, de catalogación en el marco de una biblioteca local, o una Biblioteca Mundi ${ }^{41}$. En otro artículo donde se comentaba precisamente la vertiente crítica de Riba se acude a las palabras de Anatole France para definir la «buena crítica»: «Le bon critique est celui qui raconte les aventures de son âme au milieu des chefs-d'œuvre» ${ }^{42}$.

Asimismo, en La Revista Blanca, la publicación de la familia Urales, Jacques Descleuze presentaba puntualmente su sección «El arte literario francés», espacio en el que se reseñaban algunas novedades como la traducción de las Obras escogidas de Walt Whitman, editadas por la Nouvelle Revue Française y traducidas por André Gide, Valery Larbaud, Vielé-Griffin, Jules Laforgue, Louis Fabulet o Jean Schlumberger ${ }^{43}$. Entre sus colaboradores, la revista de Frederica Montseny y la familia Urales contaba con Edmond Jaloux, renombrado crítico de Les Nouvelles littéraires. Otro signo visible de tales relaciones será el tránsito ininterrumpido de críticos y periodistas. Así es como en la prensa cultural barcelonesa podemos hallar la firma de célebres colaboradores de Les Nouvelles littéraires como Edmond Jaloux, Marcel Brion, Georges Charensol, Adolphe de Falgairolle o Jean Cassou.

En La Vanguardia destacadas son también las secciones de Augusto Assía "Crónica desde Berlín», que fomentará las relaciones entre España y Alemania con sus retratos de las personalidades más destacadas de la época, o

41. Vid. Carles Riba (firmado Jordi March), «De Sanctis», La Veu de Catalunya, 08-II.1919. En Carles Riba, Obres Completes, edición de Enric Sullà, II, Crítica, 1, Barcelona, Edicions 62, 1985, pp. 113-114.

42. Vid. Josep Maria Capdevila, "Carles Riba, crític», Revista de Catalunya, 15 de febrero de 1938, I, núm. 83, pp. 271-275. La cita de Anatole France se recoge en la página 273.

43. Véase Jacques Descleuze, «El arte literario francés», La Revista Blanca, núm. 169, 15 de mayo de 1930. 
la columna de Josep Maria Coll, "Carta desde Nueva York». Es precisamente Josep Maria Coll quien apunta en 1931 el cambio con respecto a la capitalidad del arte que terminaría por gestarse después de la Segunda Guerra Mundial. Así, en relación al trasvase París-Nueva York escribe:

Balzac comienza una de sus novelas, por un pasaje en el cual habla de que hay calles nobles, como las hay plebeyas, las hay ricas y las hay sórdidas, las hay trágicas, honradas, criminales, etc... Wall Street tiene tanto empuje y es tan ambiciosa que, habiéndose fundado hace tres centurias solamente, con cuatro míseras chozas, es hoy en día la calle donde se fraguan millones y en cuyo centro gravitan los intereses del universo entero ${ }^{44}$.

También Ramon Esquerra, desde sus Lectures europees, se distinguirá en su examen de la literatura norteamericana, análisis contradictorio si tomamos en consideración el título del libro. Desde esta perspectiva, Esquerra analizará uno de los fenómenos más importantes de la etapa de entreguerras: el paulatino decaimiento europeo en favor de la expansión norteamericana. El volumen, publicado en 1936, continuaba la línea inaugurada por Marià Manent en Notes sobre literatura estrangera (1934), libro que recogía sin embargo artículos sobre poesía y en menor grado textos sobre novela y crítica. El análisis sobre el género narrativo fue retomado por Maurici Serrahima y Rafael Tasis en Assaigs sobre la novel.la (1934) y Una visió de conjunt de la novel.la catalana (1935), respectivamente. Esquerra buscará también el apoyo extranjero e intentará equipararse con Edmond Jaloux y André Maurois, que ya habían publicado Au pays du roman (1931), y Magiciens et logiciens (1935). De Maurois, y al margen de las crónicas que relataron su discurso en el Conferencia Club en octubre de $1933^{45}$, cabe destacar un extenso artículo publicado en Meridià ante su investidura en la Academia Francesa, y un texto más analítico de Lluís Montanyà escrito para la Revista de Catalunya ${ }^{46}$.

Entre los críticos extranjeros, muy considerados estiman los juicios de Albert Thibaudet, Ernst-Robert Curtius y Stephan Zweig. Del primero se

44. Vid. Josep Maria Coll, La Vanguardia, «Carta desde Nueva York. Wall Street», 2-VI-1931, pp. 7-8.

45. Anónimo, "André Maurois en Barcelona», La Vanguardia, 07-V-1933, p. 4; Anónimo, «Conferencia Club. Los cursos de 1933-1934», 08-V-1933, p. 6, y Anónimo, «Cursos y conferencias. André Maurois en el Instituto Francés», 12-X-1933, p. 6.

46. M.A., Meridià, "André Maurois, acadèmic», 08-VII-1938, núm. 26, p. 6, y Lluís Montanyà, "André Maurois i el fantàstic científic», 15 de marzo de 1938, I, núm. 84, pp. $440-453$. 
reproduce en La Revista un artículo sobre el superrealismo; del segundo, un estudio del escritor francés Charles Peguy ${ }^{47}$. El francés Benjamin Crémieux, y el alemán Kasimir Edschmid serán también tomados en consideración. En La Vanguardia, Mario Verdaguer comenta en un agudo diálogo entre dos personajes ficticios - «El lector» $\mathrm{y}$ «El crítico»- la reciente publicación de La curación por el espíritu. Para «El crítico» la obra de Zweig, a través de tres grandes figuras -Mesmer, Freud y Mary Baker-, pone de manifiesto la crisis mundial del espíritu y la ofensiva que varios escritores han iniciado contra el actual discurso crítico. A su juicio, La curación por el espiritu está llena del «sentido trágico y desoladamente humano de una época que, manchada todavía por la ciénaga de sangre de la Gran Guerra, quiere interpretar en el fondo misterios de su propio corazón» ${ }^{48}$.

El diagnóstico de la situación de la crítica propiciará también la atención hacia otras propuestas como el socialismo idealista, corriente que los críticos catalanes examinarán probablemente a través de La Nouvelle Revue Française. Con el apoyo de la AEAR, la «Asociación de escritores y artistas revolucionarios», muchos de sus redactores se convirtieron al marxismo. Así es como la Revista de Catalunya alude al último número de la revista moscovita El llibre i la revolució proletària, publicación que contenía las respuestas de ocho renombrados escritores a la encuesta «¿Cómo es y cómo deber ser nuestra crítica literaria?» ${ }^{49}$.

Interesante también resulta la publicación en 1925, año de la polémica sobre la novela, de un artículo del crítico Edward Shanks, "Reflexions sobre la història recent de la novel.la anglesa». Tres años más tarde, Carner comentará en La Veu de Catalunya, el 17 de abril de 1928, la controvertida disputa en torno a la novela que protagonizarán François Mauriac y Paul Souday. La actuación de Mauriac como novelista e intelectual será de nuevo revalorizada por Rafael Tasis desde el triforio de la Revista de Catalunya; su ingreso en la Academia Francesa será comentado por Juan Aramburu, corresponsal en París de La Vanguardia ${ }^{50}$.

Entre los críticos ingleses, y gracias a Josep Carner, Manent se iniciaría en los trabajos críticos de William Hazlitt y The Spirit of the Age. También

47. Vid. La Revista, XI, 1925, pp. 123-125; y XI, 1925, 228, pp. 87-88.

48. Vid. Mario Verdaguer, «Los libros. La curación por el espiritu (Mesmer, Mary Baker, Freud)", La Vanguardia, 15-X-1932, p. 5.

49. Anónimo, «Notes de l'exterior», Revista de Catalunya, abril de 1934, núm. 77, pp. 93-96.

50. Vid. Rafael Tasis i Marca, «François Mauriac o la fisiologia dels àngels», Revista de Catalunya, 15 de agosto de 1938, III, núm. 89, pp. 531-550, y Juan Aramburu, «Crónicas de París. Mauriac en la Academia Francesa», La Vanguardia, 01-XII-1933, p. 3. 
en el comentario de los libros de W. H. Garrod, The Profesión of Poetry; John Livingston Lowes, Convention and Revolt in Poetry; Herbert Read, Form in modern poetry y The Innocent Eye, o Denis Thompson y F. R. Leavis, Reading and Discrimination. Sus reflexiones, publicadas en La Veu de Catalunya entre 1931 y 1934, serían publicadas en el mencionado Notes sobre literatura estrangera. Asimismo, el poeta catalán señalará a W. P. Ker, Winifred Nowottny, I. A. Richards, William Empson, F. R. Leavis, Desmond Mac Carthy, Thomas MacGreevy, y Louise Morgan; y se referirá a los estudios críticos de Chesterton, H. V. Routh, Bonamy Dobrée, Herbert J. C. Grierson y T. S. Eliot. Importantes fueron también los trabajos del crítico norteamericano Foster Damon y las opiniones de algunos profesores como E. Allison Peers, traductor al inglés de Blanquerna, El Llibre de l'Amic $i$ de l'Amat, y l'Arbre de la Filosofia d'Amor, y autor de una serie de estudios lulianos que aparecían en el Bulletin of Spanish Studies. Peers, por su parte, desde la tribuna del Times Litterary Suplement, reseñaría el último libro de Lluís Nicolau d'Olwer, y Catalunya i la República, obra de Rovira i Virgili.

En definitiva, y como se desprende de las estimaciones arriba esbozadas, la prensa cultural barcelonesa compartirá un espíritu europeísta, una vocación claramente cosmopolita, un método crítico interpretativo, y unas evidentes filias hacia la novela, género particularmente en boga. En este sentido, resultará importante el análisis que realicen sobre la novela anglosajona, la técnica controvertida del monólogo interior, la importancia del subconsciente y el sexo en las propuestas de Freud, o las teorías de Bergson.

Esquerra, Manent, Tasis, Jordana y sus coetáneos comparten su propósito de formar el gusto literario de la época. Particular importancia ofrecen Culture and Environment, de F. R. Leavis y D. Thompson que lleva el subtítulo "La educación del sentido crítico»; How to teach Reading, de F. R. Leavis; Reading and Discrimination, de Denys Thompson, y How to read, de Ezra Pound. Leavis, en How to teach Reading y en la línea que aconsejan Vossler o William Empson, recomienda el análisis profundo y riguroso. Frente al New Criticism, se postularán en favor de la biografía como punto fundamental para la comprensión de la obra de un autor. Entre sus críticos más admirados, despuntan aquellos que promueven la educación literaria y el uso de la misma por parte del lector. Ezra Pound publica un panfleto sobre la cultura literaria: "How to read». Así también lo hace Carles Soldevila en "Què cal llegir?», o Joan Estelrich en su conferencia "L'esperit amb què cal acudir a la lectura», publicada en la Revista de Catalunya en octubre de 1927. Las líneas editoriales de la mayoría de publicaciones consultadas demuestran un claro convencimiento sobre el papel fundamental de la lectura. A estos efectos, interesantes también resultan los textos publicados por E. M. Forster, 
Aspects of the novel, y Robert Mathy, Importància i futilitat de la novel.la, y un artículo aparecido en Mirador sobre las opiniones de Jaloux y Maurois, y sobre el crítico André Therive en Galerie du Temps ${ }^{51}$.

$\mathrm{Si}$ muchas de las revistas que se iniciaron entre la Gran Guerra y los principios de la Dictadura de Primo de Rivera se inclinaron hacia los estudios críticos en torno a la poesía, en las postrimerías de los años veinte, se incorporarían los ensayos relativos a la novela. Varios son todavía los trabajos parciales que pueden realizarse. Lo que parece indiscutible es el interés que manifiesta una rápida lectura sobre la prensa cultural barcelonesa de entreguerras. Sus páginas iluminan un fértil y extenso territorio que explica el pensamiento crítico catalán de los años veinte y treinta. Sus ambiciosos horizontes y amplitud de miras se nos presentan en la actualidad como un pensamiento absolutamente moderno. La lectura de revistas literarias -en inglés y en francés sobre todo-, y la reseńa de lo más granado de la literatura europea no pretendía disminuir el valor de la tradición catalana sino precisamente enriquecerla y consolidarla en el marco de la mejor literatura europea.

CLAVE: $\mathrm{L}=$ libro completo, $\mathrm{CL}=$ capítulo de libro, A=artículo, $\mathrm{R}=$ revisión/ «review», E= editor/a

1. «Recepción del pensamiento político de Unamuno en Mirador (19291937): en torno a seis artículos y otras notas», CUARDERNOS DE LA CÁTEDRA DE UNAMUNO, 45, 1, 2008.

CLAVE: A

2. Diana Sanz Roig, «La Biblia y la prosa del 27», en La Biblia y la literatura española, vol. III, Madrid, Trotta, 2009 (en prensa).

CLAVE: CL

3. Diana Sanz Roig, "Walter Benjamin y la crítica literaria española de los años veinte y treinta», Revista de Occidente, núm. 312, mayo de 2007, pp. 107-123.

CLAVE: A

4. Diana Sanz Roig, «La crítica barcelonesa en los albores de los ańos treinta", Els monogràfics de Barcelona Metròpolis. Mediterrània: Barcelona i Els Llibres. Els Llibres de Barcelona (octubre de 2006), Ayuntamiento de Barcelona, Barcelona, 2006, pp. 126-137.

CLAVE: CL

51. Vid. La Revista, 1929, 1, pp. 90-92; La Revista, 1930, 1, pp. 152-154; y Anónimo, Mirador, «Varis», núm. 138, p. 6. 